\title{
Main-chain polybenzoxazine nanofibers via electrospinning
}

\author{
Yelda Ertas, Tamer Uyar \\ Institute of Materials Science E Nanotechnology and UNAM-National Nanotechnology Research Center, Bilkent University, Ankara 06800, Turkey
}

\section{A R T I C L E I N F O}

\section{Article history:}

Received 16 September 2013

Received in revised form

22 November 2013

Accepted 9 December 2013

Available online 19 December 2013

\section{Keywords:}

Main-chain polybenzoxazines

Electrospinning

Nanofiber

\begin{abstract}
A B S T R A C T
Here we report the successful production of nanofibers from main-chain polybenzoxazines (MCPBz) via electrospinning without using any other carrier polymer matrix. Two different types of MCPBz (PBA-ad6 and PBA-ad12) were synthesized by using two types of difunctional amine (1,6-diaminohexane and 1,12diaminododecane), bisphenol-A, and paraformaldehyde as starting materials through a Mannich reaction. ${ }^{1} \mathrm{H}$ NMR and FTIR spectroscopy studies have confirmed the chemical structures of the two MCPBz. We were able to obtain highly concentrated homogeneous solutions of the two MCPBz in chloroform/ N,N-dimethylformamide (DMF) (4:1, v/v) solvent system. The electrospinning conditions were optimized in order to produce bead-free, uniform and continuous nanofibers from these two MCPBz by varying the concentrations of PBA-ad6 $(30-45 \%, w / v)$ and PBA-ad12 (15-20\%, w/v) in chloroform/DMF $(4: 1, v / v)$. The bead-free fiber morphology was evidenced under SEM imaging when PBA-ad6 and PBAad12 were electrospun at solution concentration of $40 \%$ and $18 \%(\mathrm{w} / \mathrm{v})$, respectively. The nanofibrous mats of MCPBz were obtained as free-standing material, yet, PBA-ad12 mat was more flexible than and PBA-ad6 mat. Furthermore, the curing studies of these MCPBz nanofibrous mats were performed to obtain cross-linked materials.
\end{abstract}

(c) 2013 Elsevier Ltd. All rights reserved.

\section{Introduction}

Polybenzoxazine is a newly developing phenolic type thermoset resin, which has attracted much interest in recent years because of its fascinating properties, such as near-zero volumetric change upon curing, low water absorption, high glass transition temperature, high char yield and no by-products without any catalysts during curing [1]. In addition, the molecular structure of polybenzoxazines facilitates immense design flexibility which enables tailoring the properties of the cured material for a wide range of applications [1-3]. Conventionally, benzoxazine monomers are synthesized from a phenolic derivative, a primary amine, and formaldehyde by solution or solventless method [1]. The polymerization of benzoxazines can be accomplished by means of thermally induced ring-opening reaction with or without initiator and/or catalyst. In recent years, a new type of benzoxazine has been developed in which oxazine rings are the main component of the polymer chain; main-chain polybenzoxazine (MCPBz) [1,4-20]. The $\mathrm{MCPBz}$ can be obtained by using difunctional amines and phenolic derivative, and they can also be synthesized as repeating unit of a polymer chain, block copolymer or as a side chain as well [1,4-20]. The thermal and mechanical performance of

\footnotetext{
* Corresponding author. Tel.: +90 3122903571; fax: +90 3122664365.

E-mail addresses: uyar@unam.bilkent.edu.tr, tameruyar@gmail.com, tamer@ unam.bilkent.edu.tr (T. Uyar).
}

polybenzoxazine thermosets obtained from $\mathrm{MCPBz}$ are affirmed to be excellent than those obtained from the benzoxazine monomers [12]. In other words, some of the characteristics; for instance easy processibility, flexibility, high density of crosslink after curing and lower fragility for cured end-structures were achieved for polybenzoxazines. In one respect, $\mathrm{MCPBz}$ have potentials as an easy processable and crosslinkable thermoplastic, which become thermosets at $\sim 200{ }^{\circ} \mathrm{C}$ via ring opening of oxazine ring by thermal activation [21,22].

Electrospinning is quite versatile and cost effective technique which facilitates the production of nanofibers from variety of polymers, polymer blends, sol-gels, composites and ceramics, etc $[23,24]$. In principle, a continuous filament is formed from polymer solution or polymer melt under high electric field which resulted in fibers with diameter ranging from tens of nanometers to a few microns [23]. The morphological characteristics and the diameter of the electrospun nanofibers are governed by process parameters such as applied voltage, tip-to-collector distance, flow rate of the polymer solution and nozzle diameter. On the other hand, intrinsic properties such as polymer type, molecular weight, solvent, concentration, surface tension and conductivity of the polymer solution and fluid elasticity have shown a great influence $[23,24]$. Notably, environmental conditions such as humidity and temperature also play a crucial role [23,24]. Nanofibers produced by electrospinning have several appreciable features such as a very large surface area to volume ratio and nanoscale pores. In addition, 
materials having nanofibrous structure exhibit distinctive chemical, physical and mechanical properties when compared to their bulk or film forms. The unique properties and multifunctionality of such nanofibrous structures are suitable in variety of application areas including healthcare, filtration, textiles, environmental, energy, electronics, sensors, etc [23-29].

Although a large number of studies on polybenzoxazines are appeared in the literature, only a very few reports are found in the literature on electrospinning of polybenzoxazines [30-34]. Si et al. reported on the synthesis of $1 \mathrm{D}$ mesoporous polybenzoxazine (PBZ)-based $\mathrm{Fe}_{3} \mathrm{O}_{4} @$ carbon nanofibers (CNFs) which exhibit an extremely high surface area as well as efficient adsorption for organic dyes and facilely magnetic separation property [30]. Further, the same group reported on the fabrication of 1D PBZ-based magnetic CNFs with hierarchical porous structure by a combination of electrospinning and in situ polymerization [31]. In addition, Ren et al. reported on the fabrication of hierarchical porous magnetic CNFs which comprised graphitic fibers and $\mathrm{Fe}_{3} \mathrm{O}_{4}$ nanocrystals where electrospun polyacrylonitrile/polybenzoxazine (PAN/PBZ) fibers are employed as a composite carbon source [32]. Kao et al. prepared a blend of the poly(3-phenyl-3,4-dihydro-2H-1,3benzoxazine) and PAN to produce low-surface-free-energy fibers for biononfouling membrane without fluorine and silicon elements [33]. Li and Liu reported polyelectrolyte composite membranes of polybenzimidazole and cross-linked polybenzimidazole/polybenzoxazine electrospun nanofibers for proton exchange membrane fuel cells [34]. The aforementioned studies always used additional polymers as a carrier matrix or main polymeric matrix for the electrospinning of nanofibers incorporating polybenzoxazine. However, to the best of our knowledge, this will be the first report on electrospinning of nanofiber from polybenzoxazine resins without blending with any other polymeric matrix.

In this study, we mainly focus on the optimization of electrospinning conditions in order to produce uniform and bead-free nanofibers from polybenzoxazines by itself without blending with a polymeric matrix. For this purpose, two different $\mathrm{MCPBz}$ were synthesized by using two different difunctional amine (1,6diaminohexane and 1,12-diaminododecane), bisphenol-A and paraformaldehyde as starting materials through a Mannich reaction. Afterwards, electrospinning was performed for different $\mathrm{MCPBz}$ concentrations in chloroform/DMF $(4: 1, \mathrm{v} / \mathrm{v})$ solvent system in order to produce uniform and bead-free nanofibers from these two MCPBz. Furthermore, curing studies were performed to obtain thermoset polybenzoxazine nanofibers, yet, MCPBz nanofibers could not retained their fibrous structure due to their low melting point.

\section{Experimental}

\subsection{Materials}

Paraformaldehyde (Sigma-Aldrich, 95\%), bisphenol-A (SigmaAldrich, 97\%), 1,6-diaminohexane (Aldrich, 98\%) and 1,12diaminododecane (Aldrich, 98\%) were used without further purification. Chloroform (Sigma-Aldrich, 99\%), N,N-dimethylformamide (DMF, Fluka, 98\%), methanol (Sigma-Aldrich, 99.7\%) and tetrahydrofuran (Merck, 99.7\%) were used as received. FTIR grade potassium bromide (Sigma-Aldrich, 99\%) and deuterated chloroform (Merck, 99.8\%) were used for FTIR and NMR spectroscopies, respectively.

\subsection{Synthesis of main-chain polybenzoxazines (MCPBz); PBA-ad6 and PBA-ad12}

Two different types of $\mathrm{MCPBz}$ were synthesized from two different difunctional amines (1,6-diaminohexane and 1,12-diaminododecane), bisphenol-A and paraformaldehyde as starting materials by using solvent method. The MCPBz named as PBA-ad6 was synthesized from 1,6-diaminohexane (25 mmol), bisphenol-A (25 mmol) and paraformaldehyde $(100 \mathrm{mmol})$ in a $1: 1: 4 \mathrm{M}$ ratios. Reactants were taken in a $500-\mathrm{mL}$ round-bottom flask and $250 \mathrm{~mL}$ of chloroform was added to the reaction mixture. Then, the solution mixture was refluxed for $7 \mathrm{~h}$ at $60^{\circ} \mathrm{C}$. Afterwards, chloroform was evaporated completely from the solution by using rotary-evaporator system and the product were dried under vacuum at $45{ }^{\circ} \mathrm{C}$ for $24 \mathrm{~h}$. In order to remove any residual reactants, PBA-ad6 was purified by washing through with cold methanol several times and then dried under vacuum at $45{ }^{\circ} \mathrm{C}$ for $24 \mathrm{~h}$. Overall yield of the synthesized PBA-ad6 was $83 \%$. According to the GPC measurements, weight average molecular weight $\left(M_{\mathrm{W}}\right)$ and polydispersity index of this sample was calculated as $\sim 11,500$ and 4.7 , respectively. Similar procedure was followed for the synthesis of PBA-ad12; 1,12-diaminododecane (25 mmol), bisphenol-A (25 mmol) and paraformaldehyde $(100 \mathrm{mmol})$ were put in a $500-\mathrm{mL}$ round-bottom flask and $250 \mathrm{~mL}$ of chloroform was added to the reaction mixture. In this case, the solution was refluxed for $10 \mathrm{~h}$ at $60^{\circ} \mathrm{C}$. For PBA-ad12, the drying and purification steps were same as PBA-ad6. Overall yield of the synthesized PBAad 12 was $71 \%$. According to the GPC measurements, weight average molecular weight $\left(M_{\mathrm{w}}\right)$ and polydispersity index of this sample was calculated as $\sim 17,000$ and 5.3 , respectively.

\subsection{Electrospinning of PBA-ad6 and PBA-ad12 nanofibers}

The homogenous solutions of MCPBz (PBA-ad6 and PBA-ad12) were prepared in different concentration in chloroform/DMF mixture solvent system (chloroform:DMF; 4:1, v/v). For the electrospinning of PBA-ad6 nanofibers, solution concentration was varied from $30 \%$ to $45 \%$ (w/v) and the clear and light yellow color solutions were obtained after stirring for $3 \mathrm{~h}$ at room temperature. For the electrospinning of PBA-ad12 nanofibers, 15\%, 18\% and 20\% $(\mathrm{w} / \mathrm{v})$ solution concentrations were prepared and solutions were stirred for $6 \mathrm{~h}$ to obtain a clear and homogenous solutions. The solutions were taken in $1 \mathrm{~mL}$ syringes with metallic needle of $0.6 \mathrm{~mm}$ outer diameter. The syringe was positioned horizontally on the syringe pump (KD Scientific, KDS 101) and the positive electrode of the high voltage power supply (Matsusada Precision, AU Series) was clamped to the metal needle (Fig. 1). In order to optimize the electrospinning parameters, flow rate of the polymer solution $(0.5-1.5 \mathrm{~mL} / \mathrm{h})$, applied voltage $(10-20 \mathrm{kV})$ and tip-tocollector distance $(10-20 \mathrm{~cm})$ were varied within the ranges given in the parenthesis. The most favorable results were obtained when the electrospinning parameters are $0.5 \mathrm{~mL} / \mathrm{h}, 12.5 \mathrm{kV}, 10 \mathrm{~cm}$ for the electrospinning of PAB-ad6 nanofibers and $1 \mathrm{~mL} / \mathrm{h}, 15 \mathrm{kV}$, $15 \mathrm{~cm}$ for the electrospinning of PAB-ad12 nanofibers. In all cases, the electrospinning was carried out in a horizontal position at $24{ }^{\circ} \mathrm{C}$ and $18 \%$ relative humidity in a completely enclosed plexiglas box. Electrospun nanofibers were collected on a grounded stationary cylindrical metal collector covered by a piece of aluminum foil. After the electrospinning, the collected nanofibrous mats were dried over night at $25{ }^{\circ} \mathrm{C}$ under vacuum in order to remove any residual solvent.

\subsection{Measurements and characterization}

The structure of the synthesized PBA-ad6 and PBA-ad12 were confirmed by proton nuclear magnetic resonance $\left({ }^{1} \mathrm{H}\right.$ NMR, Bruker Advance III $400 \mathrm{MHz}$ ) spectrometer. Samples were prepared by dissolving about $20 \mathrm{mg} / \mathrm{mL}$ polybenzoxazines in deuterated chloroform $\left(\mathrm{CDCl}_{3}\right)$. ${ }^{1} \mathrm{H}$ NMR spectra of the samples were measured with 16 scans in the range of $0-10 \mathrm{ppm}$. Fourier transform infrared (FTIR, Bruker-VERTEX70) spectrometer was employed to verify the 


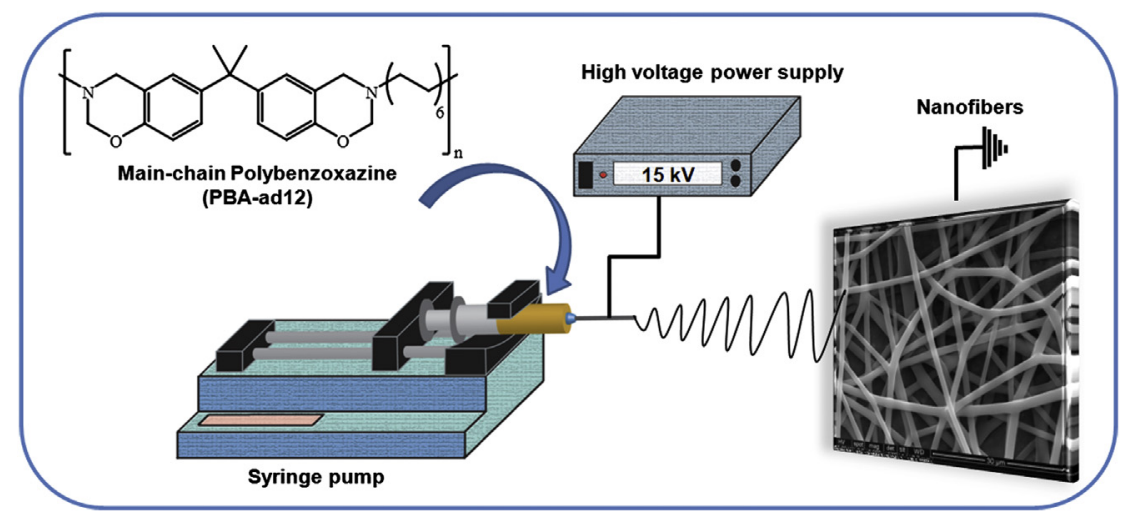

Fig. 1. Schematic diagram of the formation of main-chain polybenzoxazine nanofibers by electrospinning technique.

structure of the synthesized compounds and also ring opening of PBA-ad6 and PBA-ad12 during the curing process. FTIR spectra were obtained with 64 scans at a resolution of $4 \mathrm{~cm}^{-1}$ within $4000-400 \mathrm{~cm}^{-1}$ range. Cured PBA-ad6 samples were prepared by grinding with $\mathrm{KBr}$ in a ratio around 3:100 (3 mg sample:100 mg $\mathrm{KBr}$ ) and then compressed to form discs. On the other hand, PBAad12 nanofibrous mat formed very fine film during the thermal treatment thus, its FTIR spectra was taken directly from the film without mixing with $\mathrm{KBr}$. Molecular weight and molecular weight distribution of the PBA-ad6 and PBA-ad12 were determined by gel permeation chromatography (GPC, Waters) equipped with Waters 515 HPLC pump, Stragel HR 3-4 columns and refractive index detector. THF used as the mobile phase at a flow rate of $1 \mathrm{~mL} / \mathrm{min}$. Samples were dissolved in the THF at approximately $10 \mathrm{mg} / \mathrm{mL}$ (PBA-ad6) and $5 \mathrm{mg} / \mathrm{mL}$ (PBA-ad12) and filtered through a $0.45 \mathrm{~mm}$ teflon filter prior to being injected. Calibration of the system was performed with polystyrene standards having molecular weight of $500-1 \times 10^{6} \mathrm{~g} / \mathrm{mol}$. Calibration curve obtained from PS standards with $\mathrm{K}\left(1.9 \times 10^{-4} \mathrm{dL} / \mathrm{g}\right)$ and $\alpha(0.68)$ values at room temperature in THF solvent were used for the calculation. Molecular weights of the samples were calculated by using same $\mathrm{K}$ and $\alpha$ values as the PS standards. A rheometer (Physica MCR 301, Anton Paar) equipped with a cone/plate accessory (D:25 mm) was used to measure the viscosity of the PBA-ad6 and PBA-ad12 solutions in chloroform/ $\operatorname{DMF}(4: 1, \mathrm{v} / \mathrm{v})$ with a constant shear rate of $100 \mathrm{~s}^{-1}$ at $22^{\circ} \mathrm{C}$. Results recorded with 33 rotation of the cone/plate for each sample and averages of these measurements were calculated. Scanning electron microscope (SEM, Quanta 200 FEG, FEI) was used to investigate the morphology and the diameter distribution of nanofibers. Samples were coated with $5 \mathrm{~nm} \mathrm{Au/Pd} \mathrm{(PECS-682)} \mathrm{prior} \mathrm{to} \mathrm{the} \mathrm{SEM}$ imaging and the average fiber diameter (AFD) was calculated by analyzing around 100 fibers from the SEM images. Differential scanning calorimetry (DSC, TA Instruments Q20) experiments were conducted to study thermal transitions of MCPBz nanofibrous mats under nitrogen atmosphere at a heating rate of $10^{\circ} \mathrm{C} / \mathrm{min}$. Thermal stability experiments were carried out with thermogravimetric analyzer (TGA, Q500, TA Instruments) by starting from room temperature to $800^{\circ} \mathrm{C}$ under nitrogen gas at a heating rate of $20^{\circ} \mathrm{C} / \mathrm{min}$.

\subsection{Curing studies of PBA-ad6 and PBA-ad12 nanofibrous mats}

In order to obtain cross-linked polybenzoxazine, curing experiments were performed for PBA-ad6 and PBA-ad12 nanofibrous mats in a standard temperature control oven. Initially, a piece of sample $(\sim 2 \times 5 \mathrm{~cm})$ from each nanofibrous mat were put in the oven and kept for $1 \mathrm{~h}$ at different temperatures $\left(50^{\circ} \mathrm{C}, 60^{\circ} \mathrm{C}, 75^{\circ} \mathrm{C}\right.$, $90{ }^{\circ} \mathrm{C}, 100^{\circ}$ and $120^{\circ} \mathrm{C}$ ) separately to observe the change in fiber morphology with thermal treatment. Afterwards, step curing was performed for PBA-ad6 and PBA-ad12 mats by heating additional $1 \mathrm{~h}$ at each temperature $\left(75^{\circ} \mathrm{C}, 90^{\circ} \mathrm{C}, 120^{\circ} \mathrm{C}, 150{ }^{\circ} \mathrm{C}, 180{ }^{\circ} \mathrm{C}\right.$ and $220^{\circ} \mathrm{C}$ ) and small amount of sample was taken from each $\mathrm{MCPBz}$ mat at different temperatures to investigate the ring opening reaction by FTIR.

\section{Results and discussion}

\subsection{Structural characterization of PBA-ad6 and PBA-ad12}

Two different types of MCPBz; PBA-ad6 and PBA-ad12 were synthesized in solution by using difunctional amines (1,6diaminohexane and 1,12-diaminododecane), bisphenol-A and paraformaldehyde as precursors. The structure of the synthesized PBA-ad6 and PBA-ad12 were confirmed by ${ }^{1} \mathrm{H}$ NMR and FTIR spectroscopies (Fig. S1 and S2; see in Supporting Information).

The proposed chemical structures and ${ }^{1} \mathrm{H}$ NMR spectra of PBAad6 and PBA-ad12 are given in Fig. S1. The characteristic benzoxazine resonances attributed to the methylene units of oxazine ring; $\mathrm{O}-\mathrm{CH}_{2}-\mathrm{N}$ and the $\mathrm{Ar}-\mathrm{CH}_{2}-\mathrm{N}$ raised as singlets at 3.94 and $4.82 \mathrm{ppm}$ for PBA-ad6 and 3.95 and 4.84 ppm for PBA-ad12, respectively. Resonance bands of aliphatic protons were observed at 1.36 and $2.73 \mathrm{ppm}$ for PBA-ad6, and 1.27 and $2.74 \mathrm{ppm}$ for PBA-ad12. In addition, resonance bands of methyl group protons of bisphenol-A appeared at $1.60 \mathrm{ppm}$ as singlet and aromatic structure resonance bands observed at 6.68-6.98 ppm region as multiplet for both of the polybenzoxazine [20,35-37]. In brief, the ${ }^{1} \mathrm{H}$ NMR data confirm the successful synthesis of the two MCPBz. Moreover, generally resonance around $3.7 \mathrm{ppm}$ assigned for the Mannich bridge protons of open oxazine rings were not observed in the ${ }^{1} \mathrm{H}$ NMR spectra of synthesized MCPBz. The ${ }^{1} \mathrm{H}$ NMR results indicated that the synthesized MCPBz were free of ring-opened oligomers and purification with cold methanol was good enough to obtain high purity MCPBz.

Fig. S2 represents the FTIR spectra of the PBA-ad6 and PBA-ad12. In the case of FTIR data, the characteristic peaks of the benzoxazine structure were observed at exactly the same wavenumbers with different intensities for both MCPBz. Initially, existence of the strong band at $936 \mathrm{~cm}^{-1}$ which is ascribed to the benzene ring mode that is attached to the oxazine ring was the great evidence for the synthesis of target MCPBz. In addition, the very intense and sharp band existing at $1503 \mathrm{~cm}^{-1}$ is due to the in-plane $\mathrm{CH}$ bending mode of the tri-substituted benzene ring and the strong band appearing at $1232 \mathrm{~cm}^{-1}$ is due to the aromatic ether stretching of $\mathrm{C}-\mathrm{O}-\mathrm{C}$. These peaks confirmed the presence of benzoxazine ring structure in MCPBz samples. Apart from these, strong and sharp 
bands were observed at 2928 and $2848 \mathrm{~cm}^{-1}$ correspond to the antisymmetric and symmetric stretching of $\mathrm{CH}_{2}$ groups in the aliphatic regions. Relatively medium intensity band at $824 \mathrm{~cm}^{-1}$ is from the $\mathrm{CH}$ out-of-plane bending mode of the tri-substituted benzene rings. The FTIR spectra of MCPBz samples correlate with the literature [35-38] and prove that the synthesis of PBA-ad6 and PBA-ad12 were successfully achieved.

\subsection{Electrospinning of PBA-ad6 nanofibers}

Electrospinning of PBA-ad6 nanofibers was achieved by using chloroform/DMF $(4: 1, \mathrm{v} / \mathrm{v})$ solvent system. The concentration of the PBA-ad6 solution was varied from $30 \%$ to $45 \%(\mathrm{w} / \mathrm{v})$ to find out the most favorable concentration required for bead-free and uniform nanofibers. Table 1 summarizes the properties of PBA-ad6 solutions and the morphological features of the electrospun nanofibers. When the concentration of the solution increased from $30 \%$ to $45 \%$ $(\mathrm{w} / \mathrm{v})$, the viscosity of the solution increased as well. This is an expected result which is due to the higher number of polymer chain entanglement and overlapping at higher solution concentration.

Fig. 2 represents the SEM images and fiber diameter distribution of PBA-ad6 nanofibers electrospun from $30 \%, 35 \%, 40 \%$, and $45 \%$ (w/ v) polymer solutions. Electrospinning of $30 \%(\mathrm{w} / \mathrm{v})$ PBA-ad6 solution resulted beaded morphology with ultrafine fibers having diameter range of $100-400 \mathrm{~nm}($ AFD $=260 \pm 70 \mathrm{~nm}$ ) (Fig. 2a,b). At low solution viscosity, it is common to observe beads along with the fibers because of the higher amount of solvent and fewer chain entanglements causing a prevailing effect during electrospinning $[23,39]$. As the polymer concentration increased from 30\% to $35 \%$ $(w / v)$, the number of beads decreased dramatically and elongated beaded nanofibers in the range of $300-1000 \mathrm{~nm}$ diameter $(A F D=590 \pm 138 \mathrm{~nm}$ ) were produced (Fig. 2c,d). This is due to the relatively lower viscosity which resulted in destabilization of the electrified jet during the electrospinning process and thus caused the formation of elongated beads instead of uniform fibers. When the polymer concentration reached to $40 \%(\mathrm{w} / \mathrm{v})$ in solution, transformation from beaded nanofibers to bead free nanofibers was achieved. The increase in the viscosity which is due to the higher polymer chain entanglements in the solution is required for the electrospinning jet to be fully stretched for uniform fiber formation [23]. Bead-free nanofibers were produced at $40 \%(\mathrm{w} / \mathrm{v})$ and $45 \%$ $(w / v)$ for PBA-ad6 solutions emphasizing the requirement of high solution viscosity. However, nanofibers electrospun from $40 \%$ (w/v) PBA-ad6 solution were more uniform and finer $($ AFD $=745 \pm 136 \mathrm{~nm}$, fiber diameter distribution: 400-1100 nm) than the that of $45 \%(\mathrm{w} / \mathrm{v})$ PBA-ad6 solution (AFD $=1618 \pm 576 \mathrm{~nm}$, fiber diameter distribution: 400-3200 nm)(Fig. 2e-h). Notably, with the increase in viscosity/concentration, the diameter of the electrospun fiber also increases. As it is observed from the SEM images (Fig. 2), the diameter of PBA-ad6 nanofibers spanned from nanometer to micron scale when the concentration of the polymer solution increased. The reason for increase in fiber diameter is the greater resistance of the solution to be stretched because of the more chain entanglements at higher polymer concentration [23].

\subsection{Electrospinning of PBA-ad12 nanofibers}

Electrospinning of PBA-ad12 nanofibers was also performed in chloroform/DMF $(4: 1, \mathrm{v} / \mathrm{v})$ solvent system similar to that of PBAad6. According to GPC measurements, PBA-ad12 has a higher molecular weight ( $\mathrm{Mw} \sim 17,000$ ) than PBA-ad6 ( Mw 11,500) because of its longer alkyl chain structure. As it is known, the molecular weight of the polymer stand for the length of the polymer chain, which affects the viscosity of the solution since the polymer chain length determines the amount of entanglement of chains in a solvent [23]. Therefore the solution properties and electrospinning parameters of this polymer is expected to be different. Table 1 summarizes the solution characteristics and the morphological findings of the electrospun PBA-ad12 nanofibers. As mentioned earlier, higher molecular weight and longer chain causes more chain entanglements, thus electrospinning of PBA-ad12 was performed at relatively lower polymer concentrations. For this polymer, nanofibers were electrospun from $15 \%, 18 \%$ and $20 \%$ $(\mathrm{w} / \mathrm{v})$ polymer solutions to determine the most suitable concentration for obtaining bead-free and uniform nanofibers. Fig. 3 illustrates the SEM images of the nanofibers electrospun from these three solutions. Although, the concentrations of the solutions were very close to each other, there was distinct differences between the viscosities (Table 1) of these solutions which greatly affect the morphology and the AFD of the resulting electrospun nanofibers (Fig. 3). As it is observed from the SEM images, 15\% (w/v) PBA-ad12 solution yielded beaded nanofibers having diameter range of 200$750 \mathrm{~nm}($ AFD $=430 \pm 110 \mathrm{~nm}$ ) because of the low viscosity of the polymer solution (Fig. 3a,b). Solely, bead-free and uniform nanofibers were obtained when the PBA-ad12 solution concentration was at $18 \%(\mathrm{w} / \mathrm{v})$. The diameter of the nanofibers electrospun from $18 \%(\mathrm{w} / \mathrm{v})$ PBA-ad12 solution was ranging between 400 and $1500 \mathrm{~nm}(\mathrm{AFD}=805 \pm 220 \mathrm{~nm})$ (Fig. 3c,d). It is a typical behavior of polymeric systems in the electrospinning process that beaded nanofibers transform to bead-free fibers when the concentration and/or viscosity of the polymer solution is optimized [23]. The viscosity of this solution was high enough to stretch with electrified continuously resulting in a bead-free and continuous morphology. When the concentration of the PBA-ad12 solution increased to $20 \%(\mathrm{w} / \mathrm{v})$, the fiber diameter distribution became broader (1000$3200 \mathrm{~nm}$ ) and the diameters of the fibers became thicker (AFD $=1840 \pm 610 \mathrm{~nm}$ ) because of the high solution viscosity (Fig. 3e,f).

\subsection{Curing studies of PBA-ad6 and PBA-ad12 nanofibrous mats}

Nanofibrous mats obtained from these two MCPBz have shown some differences in mechanical properties. PBA-ad6 nanofibrous mat was kind of delicate and could not be separated from the aluminum foil completely in one piece (Fig. 4a). On the other hand, PBA-ad12 nanofibrous mat can be easily handled and it has a flexible characteristic (Fig. 4b). Moreover, their thermal properties are also different from each other because of the difference in their chemical structures.

Table 1

The characteristics of the PBA-ad6, PBA-ad12 solutions and their electrospun fibers.

\begin{tabular}{|c|c|c|c|c|c|}
\hline Solutions & $\%$ Polymer (w/v) & Viscosity $(\mathrm{Pa} \cdot \mathrm{s})$ & Average fiber diameter (nm) & Diameter range $(\mathrm{nm})$ & Fiber morphology \\
\hline PBA-ad6_30\% & 30 & 0.29 & $260 \pm 70$ & $100-450$ & Beaded nanofibers \\
\hline PBA-ad6_35\% & 35 & 0.59 & $590 \pm 140$ & $300-1000$ & Beaded nanofibers \\
\hline PBA-ad6_40\% & 40 & 0.77 & $745 \pm 140$ & $400-1100$ & Bead-free nanofibers \\
\hline PBA-ad6_45\% & 45 & 1.15 & $1620 \pm 580$ & $400-3200$ & Bead-free nanofibers \\
\hline PBA-ad12_15\% & 15 & 0.46 & $430 \pm 110$ & $200-700$ & Beaded nonofibers \\
\hline PBA-ad12_18\% & 18 & 1.24 & $805 \pm 220$ & $400-1500$ & Bead-free nonofibers \\
\hline PBA-ad12_20\% & 20 & 2.73 & $1840 \pm 610$ & $1000-3200$ & Bead-free microfibers \\
\hline
\end{tabular}



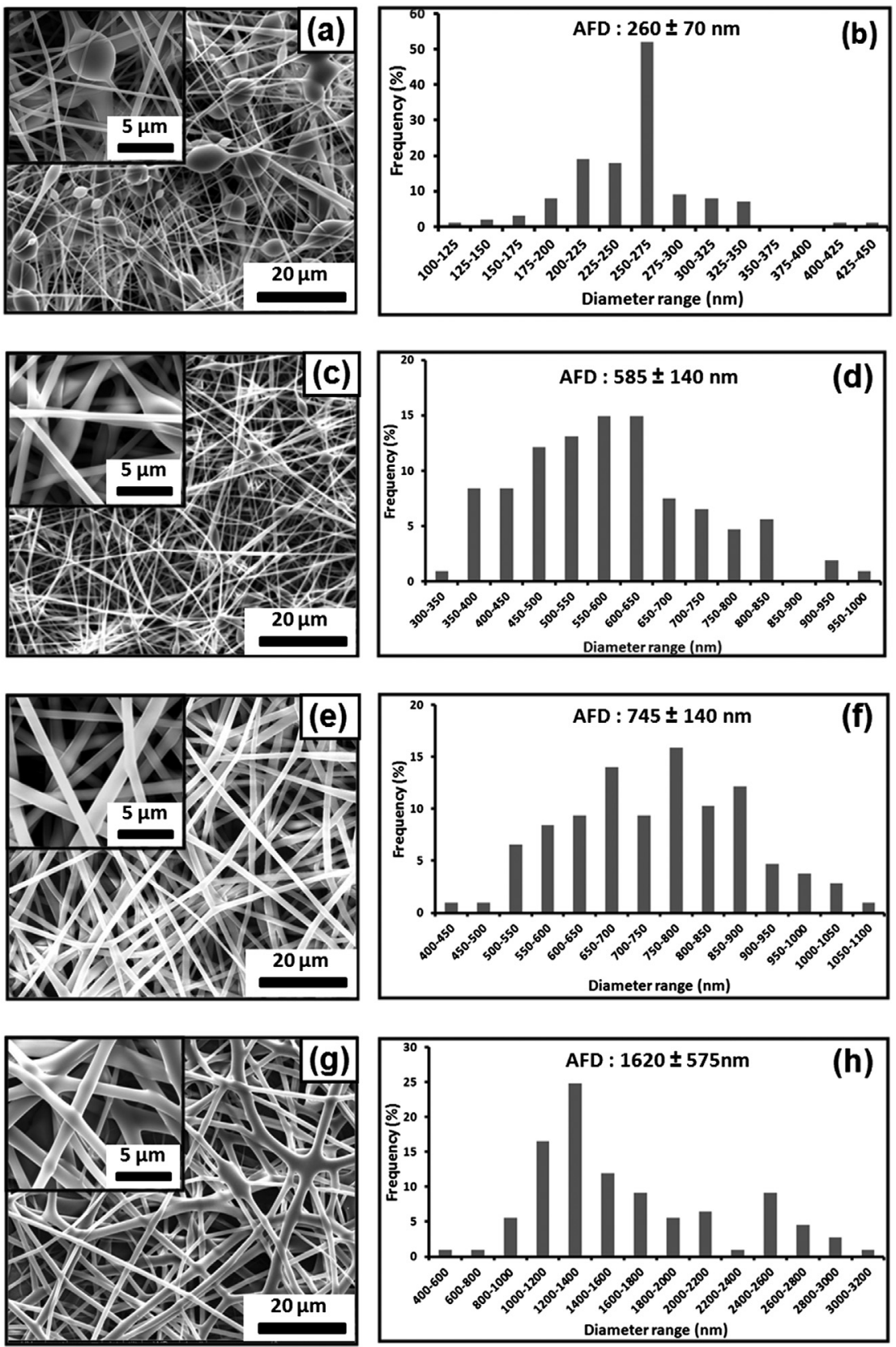

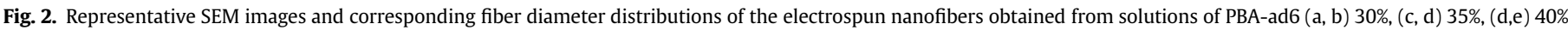
and $(\mathrm{g}, \mathrm{h}) 45 \%$. Inset shows magnified view of a typical region.

Fig. 5 shows the DSC thermograms of PBA-ad6 and PBA-ad12 nanofibrous mats. Melting transition was observed for PBA-ad6 and PBA-ad12 nanofibrous mats at $73{ }^{\circ} \mathrm{C}$ and $42{ }^{\circ} \mathrm{C}$, respectively. This difference possibly arised from the longer alkyl chain of PBAad12 which caused the decrease in the melting point. In addition, two exothermic overlapping peaks centered at $205{ }^{\circ} \mathrm{C}$ and $253{ }^{\circ} \mathrm{C}$ for PBA-ad6; $203{ }^{\circ} \mathrm{C}$ and $248{ }^{\circ} \mathrm{C}$ for PBA-ad12 nanofibrous mats appeared in the DSC thermograms. The low temperature peaks could be attributed to the crosslinking reaction (of methylol groups) and the higher temperature peaks assigned to typical benzoxazine polymerization by the consumption of benzoxazine groups in the main chain [20].

Conventionally, benzoxazine monomers and $\mathrm{MCPBz}$ are able to form cross-linked thermosets polybenzoxazines at $\sim 200{ }^{\circ} \mathrm{C}$ by thermally activated ring opening polymerization [1]. In order to investigate the crosslinking behavior of PBA-ad6 and PBA-ad12 nanofibers, curing experiments were performed for these two nanofibers. Although melting transitions were observed in the DSC thermograms of the PBA-ad6 and PBA-ad12 nanofibers, SEM images were also taken from two $\mathrm{MCPBz}$ nanofibers after each temperature step to confirm the melting of nanofibers with thermal treatment (Fig. 6). As it is observed from the SEM images (Fig. 6c,d), PBA-ad6 nanofibers have already started melting at $\sim 90{ }^{\circ} \mathrm{C}$ and completely melted at $120{ }^{\circ} \mathrm{C}$. The fiber structure is deteriorated and a film formed. On the other hand, PBA-ad12 nanofibers started to melt at relatively lower temperatures, $\sim 50{ }^{\circ} \mathrm{C}$ and completely melted at $75^{\circ} \mathrm{C}$ forming a film (Fig. $6 \mathrm{~g}-\mathrm{i}$ ). This result correlates with the measured melting temperature of PBA-ad12 nanofibrous mats by DSC method. Since melting temperature was $42{ }^{\circ} \mathrm{C}$, we observed partially melted fiber 

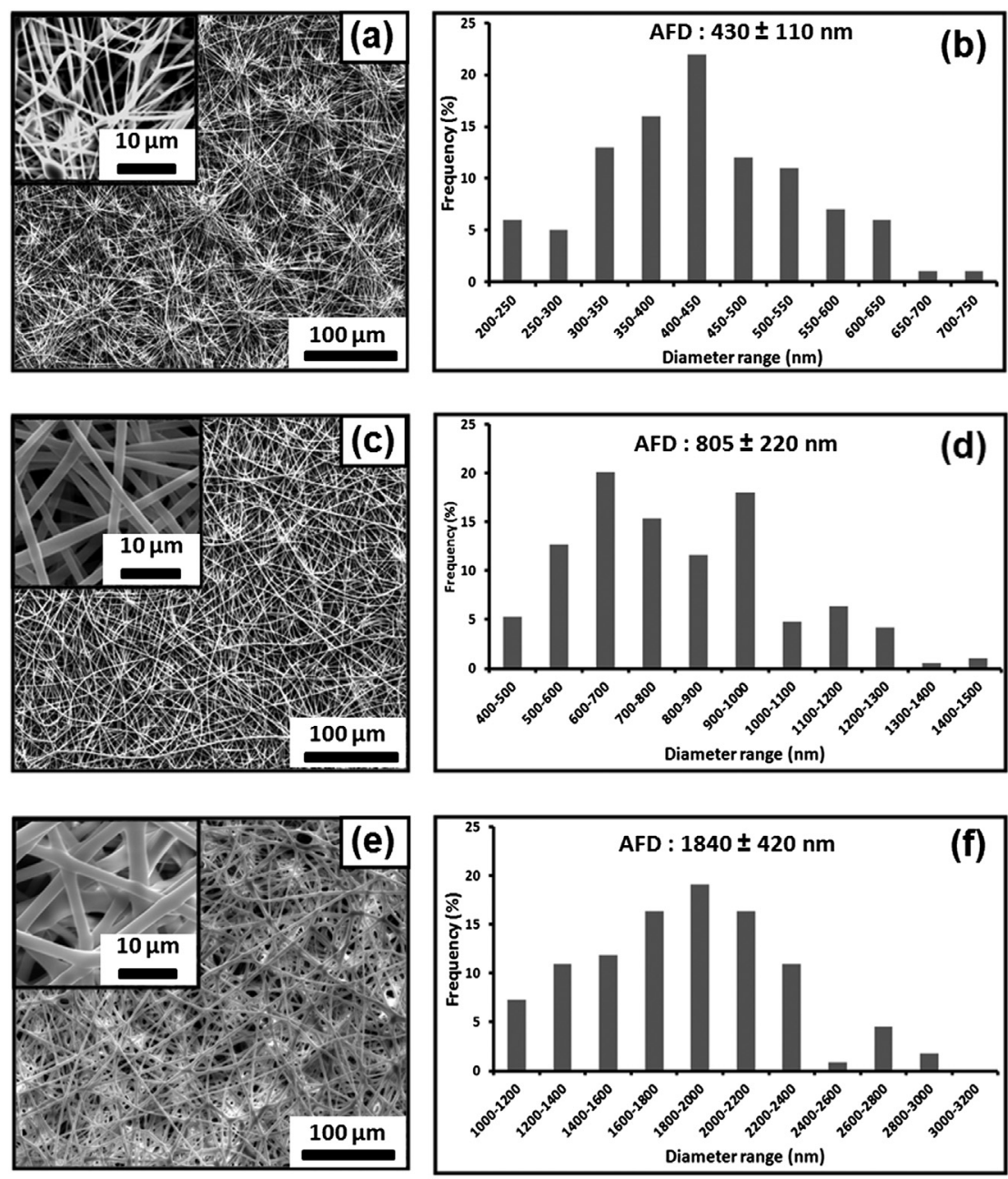

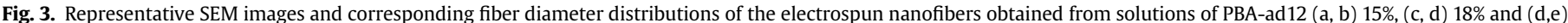
$20 \%$. Inset depicts magnified view of a typical region.

morphology after keeping this sample $1 \mathrm{~h}$ at $50{ }^{\circ} \mathrm{C}$. Consequently, PBA-ad6 and PBA-ad12 nanofibrous mats could not preserve their fiber structure during the thermal treatment because of their low melting points and they became uniform film at $120^{\circ} \mathrm{C}$ (Fig. 6e,j).
Nevertheless, curing studies were performed for these samples to determine curing temperatures of two MCPBz mats which can be used to produce composite materials by blending with other polymers.
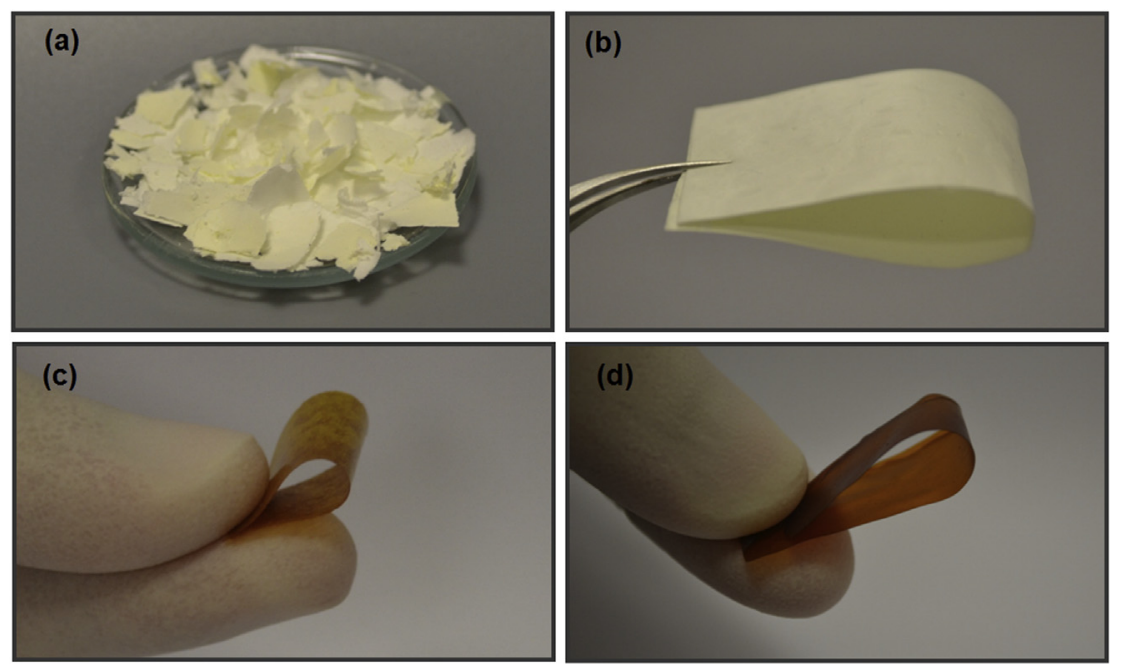

Fig. 4. Photographs of the electrospun nanowebs from (a) 40\% PBA-ad6, (b) $18 \%$ PBA-ad 12 and after curing (c) PBA-ad6, (d) PBA-ad 12 step by step at $75{ }^{\circ} \mathrm{C} ; 1 \mathrm{~h}$, $90{ }^{\circ} \mathrm{C} ; 1 \mathrm{~h}, 120{ }^{\circ} \mathrm{C}$; $1 \mathrm{~h}, 150{ }^{\circ} \mathrm{C} ; 1 \mathrm{~h}, 180^{\circ} \mathrm{C} ; 1 \mathrm{~h}$ and $220^{\circ} \mathrm{C} ; 1 \mathrm{~h}$. 

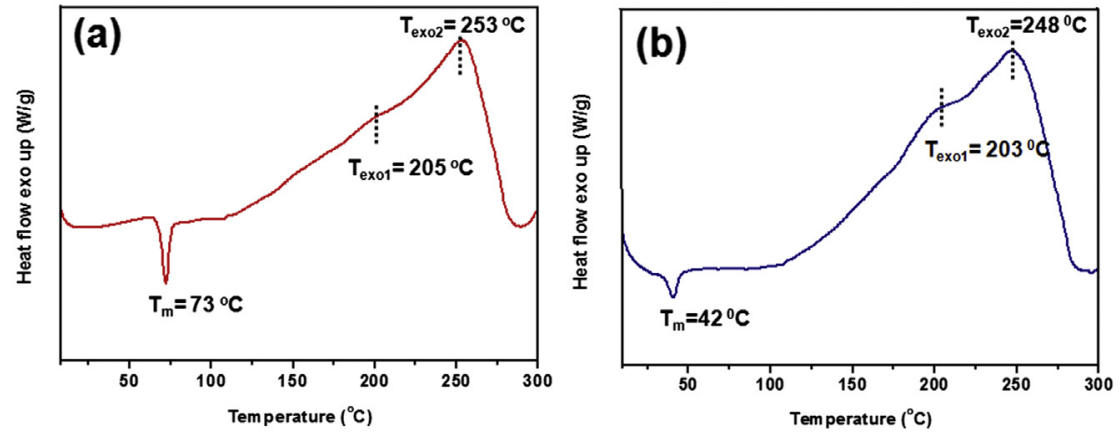

Fig. 5. DSC thermograms of (a) PBA-ad6 and (b) PBA-ad12 nanofibers.
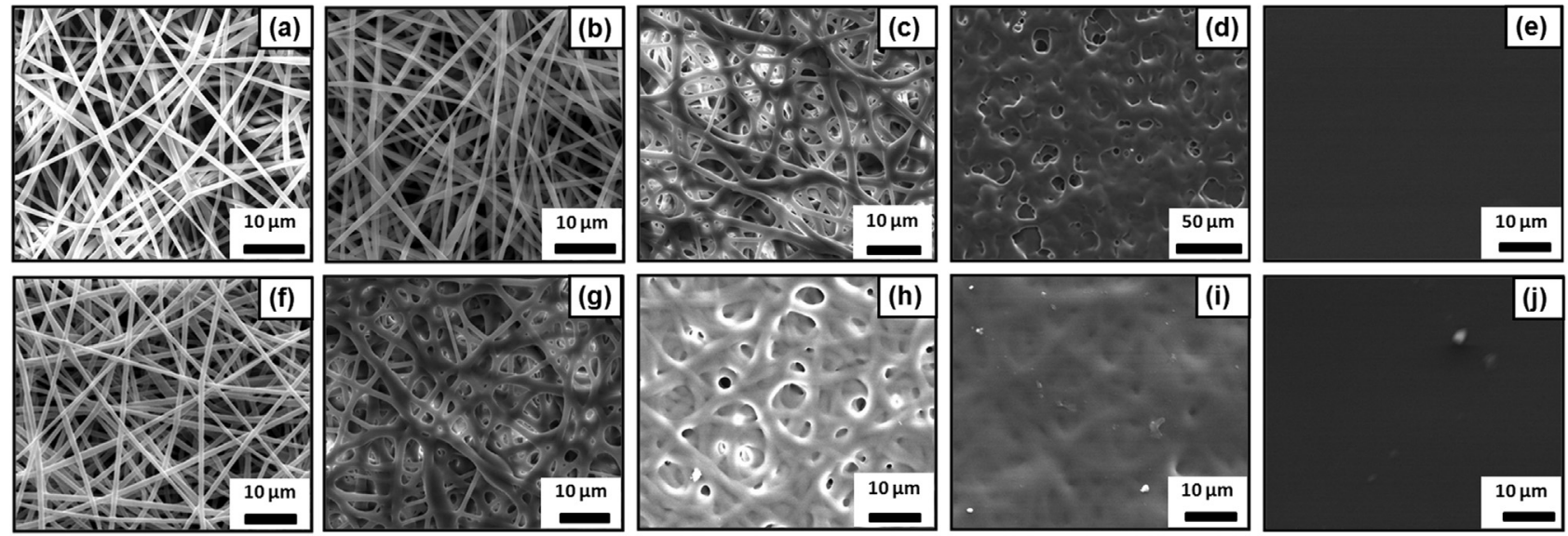

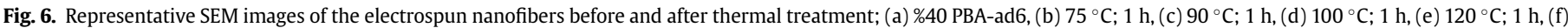
$18 \%$ PBA-ad12, (g) $50{ }^{\circ} \mathrm{C} ; 1 \mathrm{~h}$, (h) $60{ }^{\circ} \mathrm{C} ; 1 \mathrm{~h}(\mathrm{i}) 75^{\circ} \mathrm{C} ; 1 \mathrm{~h}$ and $(\mathrm{j}) 120^{\circ} \mathrm{C} ; 1 \mathrm{~h}$.

FTIR spectroscopy was used to investigate the structural changes of PBA-ad6 and PBA-ad12 films after heating at each curing temperatures, since characteristic peaks that observed at $936 \mathrm{~cm}^{-1}$ (benzene ring mode that is attached to the oxazine ring) and $1232 \mathrm{~cm}^{-1}$ (aromatic ether stretching of $\mathrm{C}-\mathrm{O}-\mathrm{C}$ ) disappear with the ring opening reaction. Therefore, we were able to determine the proper temperature that is required for complete curing. Even though, there was a remarkable difference in melting transitions of these two MCPBz nanofibrous mats, no significant change observed at their curing temperatures in DSC thermograms, thus, curing studies were performed at same temperature steps. FTIR spectra of PBA-ad6 and PBA-ad12 mats that were step cured at $75^{\circ} \mathrm{C}, 90^{\circ} \mathrm{C}$, $120^{\circ} \mathrm{C}, 150{ }^{\circ} \mathrm{C}, 180^{\circ} \mathrm{C}$ and $220^{\circ} \mathrm{C}$ for $1 \mathrm{~h}$ at each step are given in Fig. 7. As it is observed from the spectra, curing has not yet completed for both $\mathrm{MCPBz}$ mats at $120^{\circ} \mathrm{C}$ where they have fully melted and formed films (Fig 7e,j), hence, we could not obtain cross-linked nanofibers. On the other hand, intensity of peaks at $936 \mathrm{~cm}^{-1}$ and $1232 \mathrm{~cm}^{-1}$ decreased with increasing of temperature from $120^{\circ} \mathrm{C}$ to $180^{\circ} \mathrm{C}$ and peaks have almost disappeared at $220^{\circ} \mathrm{C}$ which is the sufficient temperature for the curing of these two $\mathrm{MCPBz}$ mats. This result confirms the DSC findings where curing temperatures of PBA-ad6 and PBA-ad12 mats were measured as $205^{\circ} \mathrm{C}$ and $203^{\circ} \mathrm{C}$, respectively. Finally, we obtained very fine and flexible films from both MCPBz (Fig. 4c,d).
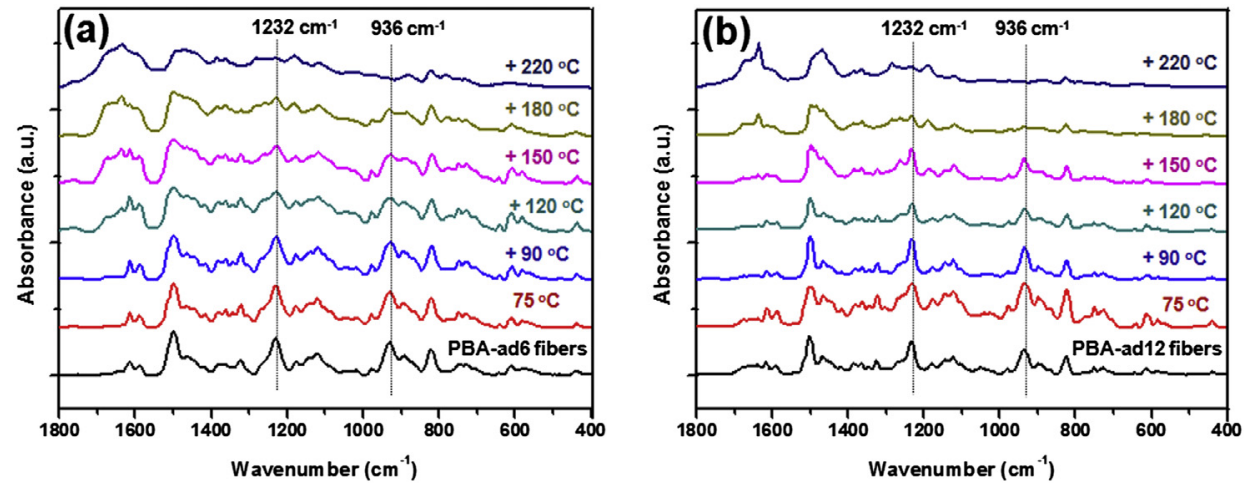

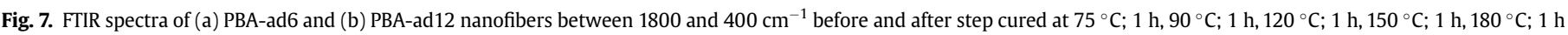
and $220^{\circ} \mathrm{C} ; 1 \mathrm{~h}$ 

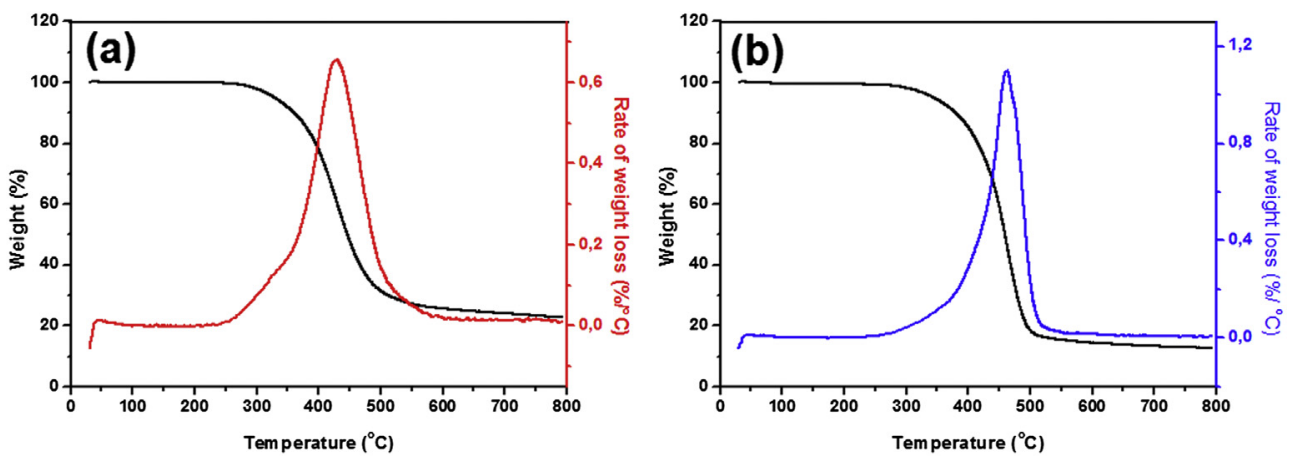

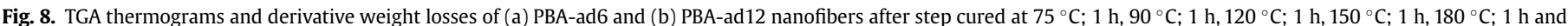
$220^{\circ} \mathrm{C} ; 1 \mathrm{~h}$.

Although, PBA-ad6 nanofibrous mat is brittle and not easily handable, after curing the sample gained better mechanical properties and we obtained more flexible cross-linked PBA-ad6 films. Yet, we observed that cured PBA-ad12 film was more flexible than cured PBA-ad6 film.

The thermal stability of MCPBz films after curing was studied by TGA. Fig. 8 shows the TGA thermograms and derivative weight losses of PBA-ad6 and PBA-ad12 films after curing. In addition to the FTIR results, one step thermal decomposition TGA thermograms also confirm the crosslinking of PBA-ad6 and PBA-ad12 films after heating up to $220{ }^{\circ} \mathrm{C}$ by step curing. $\mathrm{Td}_{5}$ and $\mathrm{Td}_{10}$ values obtained from the TGA thermograms of MCPBz films are 328 and $360{ }^{\circ} \mathrm{C}$ for PBA-ad6 films, 344 and $379{ }^{\circ} \mathrm{C}$ for PBA-ad12 films, respectively. The char yield of PBA-ad6 film is $22.8 \%$ while this value is $12.7 \%$ for PBAad12 that can be explained by the longer alkyl chain of this MCPBz. As the length of alkyl chains increased, decrease in the char yield of $\mathrm{MCPBz}$ was observed.

\section{Conclusion}

Here, we report the first study that accomplished to produce bead-free and uniform polybenzoxazine nanofibers from $\mathrm{MCPBz}$ (PBA-ad6 or PBA-ad12) without using any carrier polymeric matrices. The morphological characterization of the electrospun $\mathrm{MCPBz}$ nanofibers carried out by SEM imaging revealed that the optimal electrospinning concentrations was $40 \%$ and $18 \%(w / v)$ for PBA-ad6 and PBA-ad12, respectively. In addition, the average fiber diameter and its distribution were calculated from SEM images and corresponding values were $745 \pm 140 \mathrm{~nm}$ (between 400 and $1100 \mathrm{~nm}$ ) and $805 \pm 220 \mathrm{~nm}$ (between 400 and $1500 \mathrm{~nm}$ ) for PBAad6 and PBA-ad12, respectively. PBA-ad12 nanofibrous mat was more flexible than PBA-ad6 nanofibrous mat which was possibly resulted from the longer chain structure and higher molecular weight. The fibrous structure could not be preserved during the thermal curing of PBA-ad6 and PBA-ad12 nanofibrous mats due to the low melting point of these $\mathrm{MCPBz}$, yet, flexible and freestanding cross-linked films were obtained. As this is being the starting point of the electrospinning of polybenzoxazines without using carrier polymer matrix, this study provides the essential guidance for the production of nanofibers from different types of polybenzoxazines. Nonetheless, further developments are needed especially for the curing process without losing the fiber structure. Still, these nanofibers can be useful in composite material production with enhanced thermal and mechanical properties due to unique properties of polybenzoxazines. We anticipate that these $\mathrm{MCPBz}$ nanofibrous mats if curable while retaining their fiber morphology can be promising as high performance fibrous materials.

\section{Acknowledgment}

Dr. T. Uyar acknowledges EU FP7-PEOPLE-2009-RG Marie CurieIRG (NANOWEB, PIRG06-GA-2009-256428) and The Turkish Academy of Sciences - Outstanding Young Scientists Award Program (TUBA-GEBIP) for funding. Y. Ertas acknowledges TUBITAK (Project \# 110M612) for the PhD student scholarship.

\section{Appendix A. Supplementary data}

Supplementary data related to this article can be found online at http://dx.doi.org/10.1016/j.polymer.2013.12.018

\section{References}

[1] Ishida H, Agag T. Handbook of benzoxazine resins. Netherlands: Elsevier; 2011.

[2] Ghosh NN, Kiskan B, Yagci Y. Progr Polym Sci 2007;32:1344-91.

[3] Ishida H, Allen DJ. J Appl Polym Sci 2001;79:406-17.

[4] Demir KD, Kiskan B, Latthe SS, Demirel AL, Yagci Y. Polym Chem 2013;4: 2106-14.

[5] Demir KD, Kiskan B, Aydogan B, Yagci Y. React Funct Polym 2013;73:346-59. [6] Sawaryn C, Landfester K, Taden A. Polymer 2011;52:3277-87.

[7] Demir KD, Tasdelen MA, Uyar T, Kawaguchi AW, Sudo A, Endo T, et al. J Polym Sci Part A-Polym Chem 2011;49:4213-20.

[8] Demir KD, Kiskan B, Yagci Y. Macromolecules 2011;44:1801-7.

[9] Bagherifam S, Kiskan B, Aydogan B, Yagci Y, Hacaloglu J. J Anal Appl Pyrol 2011;90:155-63.

[10] Altinkok C, Kiskan B, Yagci Y. J Polym Sci Part A-Polym Chem 2011;49: 2445-50.

[11] Agag T, Arza CR, Maurer FHJ, Ishida H. J Polym Sci Part A-Polym Chem 2011;49:4335-42.

[12] Liu J, Agag T, Ishida H. Polymer 2010;51:5688-94.

[13] Kiskan B, Aydogan B, Yagci Y. J Polym Sci Part A-Polym Chem 2009;47:80411.

[14] Chernykh A, Agag T, Ishida H. Polymer 2009;50:382-90.

[15] Chernykh A, Agag T, Ishida H. Macromolecules 2009;42:5121-7.

[16] Velez-Herrera P, Doyama K, Abe H, Ishida H. Macromolecules 2008;41: 9704-14.

[17] Sudo A, Kudoh R, Nakayama H, Arima K, Endo T. Macromolecules 2008;41: 9030-4.

[18] Nagai A, Kamei Y, Wang XS, Omura M, Sudo A, Nishida H, et al. J Polym Sci Part A-Polym Chem 2008;46:2316-25.

[19] Kiskan B, Yagci Y, Ishida H. J Polym Sci Part A-Polym Chem 2008;46:414-20.

[20] Chernykh A, Liu JP, Ishida H. Polymer 2006;47:7664-9.

[21] Kiskan B, Yagci Y. Synthetic strategies to combine high performance benzoxazine thermosets with polymers. In: Mormann W, editor. Polychar-18 World forum on advanced materials, vol. 298; 2010. pp. 145-53.

[22] Yagci Y, Kiskan B, Ghosh NN. J Polym Sci Part A-Polym Chem 2009;47: $5565-76$.

[23] Ramakrishna S, Fujihara K, Teo W, Lim T, Ma Z. An introduction to electrospinning and nanofibers. World Scientific Publishing Company; 2005.

[24] Wendorff JH, Agarwal S, Greiner A. Electrospinning: materials, processing, and applications. Germany: Wiley-VCH; 2012.

[25] Greiner A, Wendorff JH. Angew Chem-Int Ed 2007;46:5670-703.

[26] Lagerwall JPF, McCann JT, Formo E, Scalia G, Xia YN. Chem Commun 2008: $5420-2$. 
[27] Agarwal S, Wendorff JH, Greiner A. Macromol Rapid Commun 2010;31: 1317-31.

[28] Agarwal S, Greiner A, Wendorff JH. Adv Funct Mater 2009;19:2863-79.

[29] Ramakrishna S, Fujihara K, Teo WE, Yong T, Ma ZW, Ramaseshan R. Mater Today 2006;9:40-50.

[30] Si Y, Ren T, Ding B, Yu JY, Sun G. J Mater Chem 2012;22:4619-22.

[31] Si Y, Ren T, Li Y, Ding B, Yu JY. Carbon 2012;50:5176-85.

[32] Ren T, Si Y, Yang JM, Ding B, Yang XX, Hong F, et al. J Mater Chem 2012;22: $15919-27$.
[33] Kao T-H, Chen J-K, Cheng C-C, Su C-I, Chang F-C. Polymer 2013;54:258-68.

[34] Li HY, Liu YL. J Mater Chem A 2013;1:1171-8.

[35] Nour-Eddine E, Yuan QL, Huang FR. J Appl Polym Sci 2012;125:1773-81.

[36] Yan C, Fan XY, Li J, Shen SZ. J Appl Polym Sci 2011;121:2778-87.

[37] Allen DJ, Ishida H. J Appl Polym Sci 2006;101:2798-809.

[38] Uyar T, Havelund R, Hacaloglu J, Zhou XF, Besenbacher F, Kingshott P. Nanotechnology 2009;20.

[39] Uyar T, Besenbacher F. Polymer 2008;49:5336-43. 